\title{
GAMIFICAÇÃO NA EDUCAÇÃO INFANTIL: TORNANDO VISÍVEIS AS EXPERIÊNCIAS DE UMA TURMA DE PRÉ ESCOLA DA REDE PÚBLICA DE SANTA MARIA NO TRABALHO REMOTO ${ }^{1}$
}

\author{
GAMIFICATION IN CHILDHOOD EDUCATION: MAKING VISIBLE \\ EXPERIENCES OF A PUBLIC NETWORK PRE-SCHOOL CLASS OF \\ SANTA MARIA IN REMOTE WORK
}

\author{
Deise Minuzzi Pagnossi ${ }^{2}$ e Taís Steffenello Ghisleni ${ }^{3}$
}

\section{RESUMO}

O trabalho em discussão apresenta resultados de uma prática realizada em uma instituição de Educação Infantil na cidade de Santa Maria-RS, durante o trabalho remoto com um grupo da turma criado no aplicativo Whatsapp. O estudo apresenta um relato de experiência que aconteceu em um ambiente flexível e reflexivo, pensado para a aprendizagem em que a criança é o centro do processo com um planejamento voltado, para atender as necessidades, em tempo de estar longe da escola, contemplando elementos simples e de fácil aceitação pelas famílias. Com isso, a partir de uma proposta gamificada, a turma teve a oportunidade de estabelecer um elo afetivo e desafiador, que o jogo proporciona. Dessa forma se promoveu uma aprendizagem lúdica e rica, pois para esse momento de receber as atividades em casa sem estar na escola as propostas necessitam ser envolventes e dinâmicas. Assim, foi preciso lançar desafios para que as famílias se envolvessem com as propostas, pois mesmo sabendo que a pré-escola é etapa obrigatória, algumas famílias tinham apenas um aparelho de celular para todos utilizarem, ou não tinham acesso a internet, ou ainda, não queriam realizar as propostas enviadas. Com a gamificação pode-se observar que até as famílias mais resistentes em participar do grupo da turma, gostaram da proposta e realizaram com os seus filhos.

Palavras-chave: Aprendizagem; Natureza; Jogo; Motivação

\begin{abstract}
The work under discussion presents the results of a practice carried out at an early childhood education institution in the city of Santa Maria-RS, during remote work with a group of the class created in the Whatsapp application. The study presents an experience report that took place in a flexible and reflective environment, designed for learning in which the child is the center of the process with a planning focused, to meet the needs, in time to be away from school, contemplating simple elements and easily accepted by families. Thus, from a gamified proposal, the class had the opportunity to establish an affective and challenging link, which the game provides. Thus, a playful and rich learning was promoted, because for this moment of receiving activities at home without being at school, the proposals need to be engaging and dynamic. Thus, it was necessary to launch challenges for families to get involved with the proposals, because even though they know that pre-school is a mandatory stage, some families only had a cell phone for everyone to use, or they did not have access to the internet, or even, did not want to carry out the proposals sent. With gamification, it can be observed that even the most resistant families to participate in the group of the class, liked the proposal and did it with their children.
\end{abstract}

\section{Keywords: Learning; Nature; Game; Motivation}

1 Artigo desenvolvido para a disciplina de Seminário Integrado II no Mestrado em Ensino de Humanidades e Linguagens da UFN.

2 Pedagoga. Aluna do Mestrado em Ensino de Humanidades e Linguagens da UFN. E-mail: pagdeise@yahoo.com.br 3 Orientadora. Professora do Mestrado em Ensino de Humanidades e Linguagens da UFN. E-mail: taisghisleni@ufn.edu.br 


\section{INTRODUÇÃO}

A pandemia da Covid-19 impactou os estudos dos estudantes em todo o planeta. Esse panorama assustar interfere tanto na saúde quanto nas situações de aprendizado, e sendo assim, é necessário pensar em práticas inovadoras para incentivar o interesse dos alunos utilizando a tecnologia como um instrumento facilitador desse processo.

O planejamento apresentado nesse artigo foi organizado pensando na realidade das crianças, de forma voltada para o diálogo, para a observação e a escuta, buscando colocá-las no centro do processo e garantindo que estejam totalmente envolvidas com o projeto a ser desenvolvido. Dessa forma, o trabalho remoto foi organizado pela professora de Educação Infantil, em um grupo da turma no aplicativo whatsapp, no qual propostas de atividades foram enviadas semanalmente. As atividades foram planejadas com o grupo de professores da pré escola em reuniões organizadas pelo Google Meet.

Assim, o objetivo deste artigo é expor uma atividade desenvolvida com alunos da Educação Infantil para gerar motivação no ensino aprendizagem em tempos de pandemia. Partindo dos eixos estruturantes da Educação Infantil, interações e brincadeiras, as ações e aprendizagens essenciais são pensadas a partir dos campos experiências da Base Nacional Comum Curricular - BNCC (2017), pois tão importante quanto o trabalho do professor é a interação com a família, pois as famílias que estão estabelecendo os primeiros momentos de aprendizagem em casa durante a pandemia do Covid-19.

Uma estratégia pensada para melhorar a situação de ensino aprendizagem nesse contexto foi utilizar a gamificação da sala de aula. Essa estratégia não envolve necessariamente trabalhar com jogos, mas sim transformar as aulas em uma experiência gamificada, com a inserção de regras que motivem os alunos de forma ampliada. Nesse contexto, o tema explorado foi o Jogo da Velha da Natureza, com uma turma de pré A composta de 19 crianças de 4 a 5 anos.

A proposta do Jogo da Velha da Natureza foi enviado para o grupo da turma com as orientações, em que para realizar o jogo a criança precisava recolher elementos da natureza. E que o mesmo poderia ser realizado utilizando elementos simples como carvão, giz, pedrinha, para riscar na calçada, galhos para riscar no chão, enfim as famílias poderiam utilizar o que teriam disponível em suas casas.

A experiência da gamificação com o Jogo da Velha da natureza, contempla os campos de experiência da BNCC: O eu, o outro e o nós; Espaços, tempos, quantidades, relações e transformações; Traços, sons cores e formas, pois é por meio das brincadeiras, que a criança fantasia, recria a realidade e constrói experiências significativas, que serão importantes para descobrir o mundo e se inserir em um contexto social. Assim somos direcionados a refletir:

O brincar é uma experiência de cultura importante não apenas nos primeiros anos da infância, mas durante todo o percurso de vida de qualquer ser humano. o brincar alimenta-se das referências e dos acervo cultural a que as crianças têm acesso, bem como das experiências que elas têm (FREIRE, 1986, p. 74). 
Sendo assim, o principal objetivo do planejamento desenvolvido foi de promover o brincar, a aprendizagem e a interação da criança com a família, a partir de atividades que utilizassem os elementos da natureza, materiais não estruturados e o jogo para buscar a interação e aprendizagem, a partir de atividades envolventes e desafiadoras. Oportunizar a criança o contato com os elementos naturais e aguçar a curiosidade a partir da gamificação, promoveu uma maior interação das crianças com seus familiares, proporcionando uma aprendizagem significativa e maior participação nas propostas de atividades enviadas, com o uso da gamificação. Assim somos direcionados a refletir.

Ao falar da construção do conhecimento, criticando a sua extensão, já devo estar envolvido nela, e nela, a construção, estar envolvendo os alunos. Fora disso, me emaranho na rede das contradições em que meu testemunho, inautêntico, perde eficácia. Me torno tão falso quanto quem pretende estimular o clima democrático na escola por meios e caminhos autoritários (FREIRE, 1996, p. 48).

Dessa forma, a utilização da gamificação na Educação Infantil, promove um maior envolvimento tanto da família, quanto da criança neste momento de estar longe da escola, porque é um momento de descontração, um momento dedicado a atividade proposta, que promove um maior engajamento das famílias, pois o jogo faz parte da natureza humana e possui estratégias que influenciam e promovem a socialização, a interação e a aprendizagem.

\section{DESENVOLVIMENTO DAS ATIVIDADES E ASPECTOS METODOLÓGICOS}

Considerando os conhecimentos prévios que as crianças apresentaram sobre natureza nos poucos dias de aula que tivemos nesse ano de 2020, no qual os primeiros dias foram marcados pela adaptação da turma, com choros e resistência da criança em permanecer no ambiente escolar longe de sua mãe. Para a maioria da turma foi o primeiro momento de separação de suas mães e o primeiro contato com a escola, colegas e a professora.

Foram poucos dias de interações, mas esse primeiro contato pude observar que era uma turma tranquila, participativa e que gostavam muito da hora do conto, de música e de brincar nos espaços ao ar livre da escola, principalmente em contato com a natureza, pois a mesma é uma ferramenta de aprendizado, que proporciona descobertas para esta faixa etária de 4 a 5 anos.

No dia 18 de março de 2020 as aulas foram suspensas em decorrência da pandemia e nesse momento as crianças permaneceram em suas casas com suas famílias sem poder frequentar a escola em decorrência do coronavírus. A escola promoveu diversas ações para aproximar as famílias nesse período, como distribuição de cestas básicas e promoveu diversas maneiras para arrecadar recursos, para poder distribuir alimentos para as famílias mais carentes e mais afetadas pelo efeito da pandemia. Muitas famílias da turma do Pré A Amarelo, perderam a renda, algumas mães que em muitos casos, são o chefe da família, trabalhavam como diaristas, e relataram a partir de ligação telefônica, que 
ficaram sem renda alguma, pois perderam a renda que tinham e também não tinham com quem deixar a criança enquanto estavam no trabalho.

Nesse momento de não poder estar em sala de aula com as crianças, os professores da escola receberam formação oferecida pela escola. As reuniões aconteciam pelo Google Meet, e aconteciam estudos de livros selecionados entre as professoras, para ser estudado e debatido entre o grupo de docentes. Também foram oferecidas, formação pela SMED do município. Segundo Proença (2018, p. 16), a formação docente é um processo formativo que encadeia um elo a outro de um diálogo estabelecido entre as partes de um todo,de tal forma que se mesclam em seus percursos e recompõem-se a sintonia do conjunto como uma orquestra.

Depois desse período de formação, surgiu o trabalho remoto que aconteceu a partir do dia 20 de julho de 2020, em que cada professor da escola criou um grupo da turma, no aplicativo de whatsapp, para realizar o trabalho remoto. A partir do grupo da turma é que são enviadas semanalmente orientações para as famílias com as propostas de atividades pensadas de acordo com a realidade das crianças. As propostas são sempre enviadas na segunda-feira, e as famílias têm até a outra segunda para dar o retorno da atividade, pois a pré-escola é etapa obrigatória e o retorno da criança tem que acontecer, embora muitas famílias ainda estão em processo de adaptação dessa nova realidade e não enviam as atividades.

As atividades enviadas para a turma são elaboradas em conjunto com as professoras de pré escola e em trabalho colaborativo com a professora da Educação Especial. Sempre se considera as possibilidades de interação da criança com as atividades, sendo que estas busquem elementos que todos tenham disponíveis em suas casas. São enviadas histórias em arquivo de pdf para a hora do conto, narradas pela professora com recursos como o play games, kinemaster entre outros recursos, e também disponibilizada a versão original para que as famílias possam contar para a criança nos momentos de aproximação nas suas casas, como antes de dormir.

Além da hora do conto, são enviadas atividades para a família realizar com a criança e também para o aluno Vitor (AEE), é enviada uma atividade para ser desenvolvida com a família e promover a interação com a turma, geralmente é uma atividade com música, pois a música oferece uma dinâmica mais lúdica e criativa, o lúdico faz parte da natureza humana.

Como as crianças estão constantemente brincando e a brincadeira estimula a capacidade da criança respeitar regras, que valerá não só para a brincadeira, mas também um aprendizado para a vida é que as ações pensadas para a turma acontecem com brincadeiras e jogos simples, como é o caso da proposta de atividade do Jogo da Velha da Natureza, que foi proposto para a turma durante o trabalho remoto, pois possibilita o resgate de um jogo conhecido pelo maior parte das famílias e ainda propõe a criança brincar com brinquedos não estruturados.

Segundo Freire (1986, p. 74). 
Brincar é nossa primeira forma de cultura. a cultura é algo que pertence a todos e que nos faz participar de ideais e objetivos comuns.A cultura é o jeito das pessoas conviverem e se expressarem, é o modo como as crianças brincam, como os adultos vivem, trabalham e fazem arte. Mesmo sem estar brincando com o que denominamos "brinquedo", a criança brinca com a cultura.

Assim a interação da família com a criança acontece a partir da brincadeira com um jogo de fácil aceitação e, que fez parte de muitas famílias na infância e, que além de desenvolver o brincar, faz também um resgate de uma brincadeira antiga, adaptada para o tempo de ficar em casa longe da escola, proporcionando um momento rico de aprendizado, interação e aproximação.

O Jogo da Velha da natureza oportunizou primeiramente, para as crianças do pré A Amarelo, momentos de contato com a natureza, com materiais não estruturados, pois na natureza é possível encontrar os melhores e mais variados ingredientes, como gravetos, sementes, pedrinhas, folhas... e esses contato com os elementos naturais proporcionam estreitar os vínculos afetivos, o diálogo, o partilhar. E no momento de partir para a construção do jogo as famílias se empenharam para realizá-lo de forma divertida, muitas vezes proporcionando que a criança ganhasse o jogo para se sentirem mais motivados.

Como o ensino remoto acontece por intermédio das famílias, cada familiar proporciona momentos de jogo de acordo com a sua cultura, se estivéssemos em sala de aula as regras deveriam ser seguidas, para que o objetivo do jogo fosse alcançado e a experiência da gamificação se tornasse lúdica, rica e significativa.

De acordo com Alves (2015, p. 22), o desafio mobiliza o jogo. É a mola propulsora que desafia o jogador a atingir objetivos, alcançar resultados e se superar. Mesmo o jogo mais simples está de alguma maneira desafiando o jogador. Um jogo acaba se tornando aborrecedor quando o desafio deixa de existir. Sendo assim as famílias foram desafiadas a interagirem com seus filhos através do jogo da velha da natureza, postando vídeos do jogo realizado em família no grupo da turma e assim incentivando aos outros integrantes da turma a participar.

Desde os princípio da civilização os jogos fazem parte da sociedade e das relações, sendo assim a Gamification pode ser aplicado em qualquer área onde se busque a construção de um resultado onde o princípio seja a competitividade, e dessa forma engajar as pessoas e promover a aprendizagem de forma eficaz e divertida, animando as pessoas para práticas de atividades educacionais e sociais oportunizando a leveza para que a aprendizagem aconteça de forma suave e lúdica.

Assim podemos utilizar a gamificação para tornar nossas aulas mais dinâmicas e atraentes, criando atividades educativas que motivem as crianças. O professor não precisa dominar o uso das tecnologias para fazer uma gamificação em sala de aula, ele pode usar o trabalho em grupo para isso, ou ainda usar elementos simples, para estimular a criatividade e tornar a aprendizagem em algo interessante e motivador para seu aluno.

Ainda de acordo com Alves, (2015, p. 28), somos direcionados a refletir: 
A construção de problemas se intensifica por meio dos games por sua natureza cooperativa e por vezes competitiva. aceitamos as regras do jogo, sabemos qual é a meta, concordamos em jogar com pessoas diferentes para alcançarmos os objetivos e aceitamos feedback corretivo para o alcance do resultado desejado Some a isso os aspectos do desafio e o prazer de participar da construção de algo de maneira voluntária e você terá uma grande volume de problemas resolvidos com muito mais inovação e eficácia.

A gamificação pode ser usada desde a Educação Infantil até as demais etapas da educação, pois a atividade gamificada irá proporcionar um aprendizado prazeroso que estimula a criatividade, autonomia, a aceitação de regras, o jogo potencializa o desenvolvimento integral tanto de crianças quanto de adultos, sendo possível identificar a expressão de afetos a partir do jogo, resoluções de conflitos e também controle das emoções.

Segundo Alves, (2015, p. 54), a motivação influencia tanto o processo de aprendizagem quanto o seu conhecimento anterior e experiências relacionadas ao assunto em questão. O seu estilo de aprendizagem também afeta a forma e a velocidade com que você aprende.

Sendo assim, o Jogo da velha da natureza aproximou a turma, estimulou a participação no grupo, mais do que as outras propostas de atividades, enviadas durante o período do ensino remoto do ano de 2020. Mostrando assim que a gamificação estimula e torna o aprendizado possível, mesmo em tempos de estar em casa sem poder frequentar a escola.

\section{RESULTADOS E DISCUSSÕES}

O ambiente flexível e pensado para a aprendizagem irá mostrar que permitir que a criança seja o centro do processo, faz com que elas se desenvolvam com autonomia, proporcionando ricas possibilidades de aprendizagens, por isso a importância do professor pensar em propostas de atividades que contemplem todas as famílias da turma, levando em consideração que existem diversas realidades, por isso devemos olhar, observar, escutar as crianças e proporcionar atividades que desenvolvam a autonomia e a liberdade. nesse período de trabalho remoto, em que dependemos que a família tenha acesso a internet.

Muitas vezes, nós professores planejamos nossas aulas sem ter conhecimento da realidade dos nossos alunos, a situação de vulnerabilidade social em que vivem e ainda pensamos que iremos alcançar a todos a partir de um celular, que muitas vezes é usado por todos da família para ter acesso às atividades, que a escola envia. De acordo com Gabriel, (2013, p. 109), se analisarmos a situação tecnológica atual das instituições de ensino brasileiras, temos diversos tipos de defasagens entre as públicas e as privadas, além de também estarmos em estágios diferentes se nos compararmos a países estrangeiros.

Essa pandemia veio para agravar ainda mais a desigualdade social, pois se pararmos para comparar a escola pública com a escola privada iremos observar que há uma disparidade enorme, pois as escolas privadas contam com a grande maioria de seus alunos com acesso às tecnologias, 
enquanto que a escola pública ainda busca alternativas para conseguir atender a seus alunos, buscando superar muitas dificuldades que esbarram na pobreza, pois, muitas famílias enfrentam dificuldades para oferecer o mínimo a seus filhos. Segundo o artigo $4^{\circ}$ do Estatuto da Criança e do Adolescente:

É dever da família, da comunidade, da sociedade em geral e do Poder Público assegurar, com absoluta prioridade, a efetivação dos direitos referentes à vida, à saúde, à alimentação, à educação, ao esporte, ao lazer, à profissionalização, à cultura, à dignidade, ao respeito, à liberdade e à convivência familiar e comunitária (NATUS TECNOLOGIA, 2011).

Diante desta realidade e do momento em que estamos vivendo, que as crianças precisam estar longe da escola e permanecer em suas casas realizando as atividades com a ajuda de seus familiares, é que devemos pensar que as propostas de atividades devem ser simples e pensadas para que a criança desenvolva suas habilidades sociais, afetivas, cognitivas e físicas. Sendo assim, o jogo proporciona o aprendizado, desenvolve a autonomia e promove uma interação com a família e a escola, de forma prazerosa, rica e motivadora.

Com o trabalho remoto as crianças realizaram a atividade do Jogo da Velha da Natureza com a ajuda dos seus familiares, que seguiram as orientações da professora, mas naturalmente as famílias deram uma ajudinha para que a criança ganhasse o jogo e ficassem felizes.

Se a atividade tivesse acontecido na escola, primeiramente iríamos sair pelo pátio da escola para recolher elementos da natureza, depois sentar em uma sombra para ouvir uma boa história relacionada com a natureza e preservação do meio ambiente e depois iriamos riscar o jogo da velha no chão com um galho ou conforme a turma imaginasse melhor, organizando a turma em grupos e explicando as regras do jogo. Dessa forma a turma aprenderia a respeitar as regras e brincar ao ar livre aproveitando esse momento lúdico, mas com o trabalho remoto, o que podemos fazer é incentivar as famílias a fazerem o seu melhor, para atender as necessidades da criança e assim ajudá-las a se desenvolver.

\section{CONSIDERAÇÕES FINAIS}

De acordo com a BNCC (2017), como primeira etapa da Educação Básica, a Educação Infantil é o início e o fundamento do processo educacional. A entrada na creche ou na pré-escola significa, na maioria das vezes, a primeira separação das crianças dos seus vínculos afetivos familiares para se incorporarem a uma situação de socialização estruturada. Contudo, isso exige que o docente compreenda que as crianças são capazes de criar, explorar e deve estar sempre atento a tudo que acontece, para possibilitar plena integração com a família e escola. Nesse momento tão atípico que é o trabalho remoto, o professor deve buscar ações lúdicas e simples que ofereçam à criança a oportunidade de aprender brincando e interagir com os colegas a partir da socialização das atividades através do grupo da turma.

A partir do projeto desenvolvido com o tema Jogo da Velha da Natureza, as crianças do pré A Amarelo tiveram a oportunidade de realizar atividades de forma lúdica e desafiadora, pois o jogo 
desenvolve a aprendizagem. Brincar é muito importante no contexto da Educação Infantil, porque possibilita o processo de desenvolvimento da criança e proporciona a autonomia e a criatividade. Mesmos distantes da sala de aula é importante pensar em aprendizagens significativas para a criança, o jogo possibilita que a criança busque uma motivação, uma experiência rica, divertida e prazerosa com seus familiares.

Sendo assim, a atividade do Jogo da Velha da Natureza proposta para a turma do Pré A Amarelo tornou-se uma brincadeira leve e divertida que influenciou a turma a interagir e postar vídeos da atividade no grupo da turma, no aplicativo de whatsapp. As mães relataram que no início do trabalho remoto, para a maioria das crianças, receber as propostas de atividades para fazer em casa era bem difícil, algumas porque eram tímidas, outras porque as mães não tinham formação, ou ainda porque, para a criança na escola era melhor de realizar as atividades. Aos poucos muitas crianças superaram a timidez e sentiram-se mais envolvidas com as propostas enviadas.

As mães também relataram através de questionário, para a elaboração do Relatório descritivo da criança, que quando a escola precisou ser fechada por conta da pandemia, para muitas crianças da turma do pré A Amarelo a sensação foi de tristeza e, que para outras inicialmente, foi a sensação que estavam de férias, mas que logo sentiram falta da escola e começaram a perguntar, quando iriam retornar para a escola.

Dessa forma, ao elaborar o planejamento, com as propostas de atividades, através de reuniões no Google Meet, com o grupo de professoras de pré escola, sempre se pensou em atividades que possibilitasse desenvolver a imaginação, a criatividade, o respeito pela natureza e os cuidados necessários com a mesma. Com atividades inovadoras que fugissem da ideia do papel A4; Assim as atividades possibilitam que a criança desenvolva a autonomia e a criatividade com materiais não estruturados, que fogem do convencional e deixarão marcas de uma infância vivenciada com criatividade e contato com a natureza, com a possibilidade de interagir com elementos simples e encantadores com tudo que a natureza nos disponibiliza todos os dias.

Sendo assim, foi proposto para a turma do pré A Amarelo o Jogo da Velha da natureza, que possibilitou para as famílias um momento de descontração, lúdico utilizando elementos simples da natureza, onde o jogo poderia ser desenhado na terra, areia ou calçada com elementos como pedrinha, carvão ou o próprio dedo da criança e ser jogado em família. Essa atividade teve uma boa aceitação pela maioria das famílias, porque a maioria se envolveu e ajudou a criança a recolher os elementos da natureza para montar o jogo. As famílias também se envolveram na realização do jogo, isso pode ser observado nos vídeos e fotos que enviaram no aplicativo de whatsapp do grupo da turma.

Assim a gamificação possibilitou, que a maioria das crianças do pré A Amarelo, tivessem momentos de trocas de experiências,interações,momentos ricos, descontraídos e em contato com a natureza, com materiais não estruturados com um planejamento voltado para os campos de experiência. Dessa forma, mesmo com o ensino remoto, as crianças puderam desenvolver a curiosidade, expressar 
seus aprendizados, sentimentos e também aprender regras, desenvolver a autonomia e a cooperação, elementos que a gamificação proporciona por ser lúdica e dinâmica.

\section{REFERÊNCIAS}

ALVES, Flora. Gamification: como criar experiências de aprendizagem engajadoras. Um guia completo: do conceito à prática. 2. Ed. São Paulo: DVS Editora, 2015.

BRASIL. Base Nacional Comum Curricular: Educação Infantil. Brasília: MEC/Secretaria de Educação Básica, 2018.BRASIL. Estatuto da Criança e do Adolescente. Lei 8.069/90, de 13 de julho de 1990.

BRASIL. Ministério da Educação. Base Nacional Comum Curricular (BNCC). Brasília: Ministério da Educação, 2017. Disponível em: http://basenacionalcomum.mec.gov.br/a-base. Acesso em: 11 dez. 2020.

BRASIL. Ministério da Educação e do Desporto. Secretaria de Educação Básica. Referencial Diretrizes Curriculares Nacionais para a Educação Infantil. Brasília: MEC/ SEB, 2010.

FREIRE, Madalena.dos olhares ao Espaço- Ação na Pré- Escola. Campinas: Papirus,1986.

FREIRE, Paulo. Pedagogia da autonomia: saberes necessários à pratica educativa. São Paulo. Paz e terra, 1996.

GABRIEL, Martha. Educ@r: A (r)evolução digital na educação.1.ed- São Paulo: Saraiva, 2013.

NATUS TECNOLOGIA. Instituto C. Institutoc.org.br. Disponível em: https://institutoc.org.br/. Acesso em: 11 fev. 2021.

HORN, Maria da Graça Souza. Sabores, cores, sons, aromas: a organização dos espaços na educação infantil. Porto Alegre: Artmed, 2004.

PROENÇA, Maria Alice. Prática Docente a abordagem de Reggio Emilia e o trabalho com projetos, portfólios e redes formativas.São Paulo. Panda Educação, 2018. 
